\title{
Analysis of Diversity of Diazotrophic Bacteria Associated with the Rhizosphere of a Tropical Arbor, Melastoma malabathricum $\mathbf{L}$.
}

\author{
Atsuya Sato ${ }^{1}$, TOShihiro Watanabe ${ }^{2}$, YUSUKe UnNO ${ }^{3}$, ErRy PURNOMO ${ }^{4}$, Mitsuru Osaki ${ }^{1,2}$, and \\ TAKURO SHINANO ${ }^{3 *}$ \\ ${ }^{1}$ Graduate School of Agriculture, Hokkaido University, Kita 9, Nishi 9, Kitaku, Sapporo 060-8589, Japan; \\ ${ }^{2}$ Research Faculty of Agriculture, Hokkaido University, Kita 9, Nishi 9, Kitaku, Sapporo 060-8589, Japan; \\ ${ }^{3}$ National Agricultural Research Center for Hokkaido Region (NARCH), Hitsujigaoka 1, Toyohiraku, Sapporo \\ 062-8555, Japan; and ${ }^{4}$ Center for Tropical Adverse Soil Studies Natural Resource and Environmental Management \\ Lambung Mangkurat University, PO Box 1028 Banjarbaru 70714, South Kalimantan, Indonesia
}

(Received December 8, 2008-Accepted February 4, 2009—Published online March 10, 2009)

The diversity of diazotrophic bacteria in the rhizosphere of Melastoma malabathricum L. was investigated by cloning-sequencing of the nifH gene directly amplified from DNA extracted from soil. Samples were obtained from the rhizosphere and bulk soil of M. malabathricum growing in three different soil types (acid sulfate, peat and sandy clay soils) located very close to each other in south Kalimantan, Indonesia. Six clone libraries were constructed, generated from bulk and rhizosphere soil samples, and 300 nifH clones were produced, then assembled into 29 operational taxonomic units (OTUs) based on percent identity values. Our results suggested that nifH gene diversity is mainly dependent on soil properties, and did not differ remarkably between the rhizosphere and bulk soil of M. malabathricum except in acid sulfate soil. In acid sulfate soil, as the Shannon diversity index was lower in rhizosphere than in bulk soil, it is suggested that particular bacterial species might accumulate in the rhizosphere.

Key words: nitrogen-fixing bacteria, rhizosphere, Melastoma malabathricum L., diversity

The levels of nitrogen $(\mathrm{N})$ and other minerals (phosphorus, calcium and magnesium) in acid soils $(\mathrm{pH}<4)$ are generally very low and insufficient for the growth of most plants (20). Melastoma malabathricum L. is a tropical woody plant known as an aluminum-accumulator. This plant is able to adapt to very nutrient-poor environments such as acid soils $(22,23,36)$ and is widely distributed in acid sulfate soil areas in central and south Kalimantan, Indonesia. As soil nutrient levels are quite low, the ability to acquire $\mathrm{N}$ must also be considered. We have found that $M$. malabathricum continued to grow at low N-levels in hydroponic cultures with significant increases in dry weight and $\mathrm{N}$ content, though other plants could not grow (data not shown). It has been considered that microorganisms inhabiting the rhizosphere of $M$. malabathricum may help with plant growth by supplying biologically-fixed nitrogen (BFN). Several candidate bacteria have been evaluated (13); however, they were isolated from the M. malabathricum rhizosphere, and the report did not describe the diazotrophic diversity and evaluate their contribution to $\mathrm{N}$ acquisition of M. malabathricum in an actual nutrient-poor soil.

Diazotrophic bacteria are known to directly and indirectly affect plant growth: directly through a substantial contribution of BNF to $\mathrm{N}$ acquisition of the plant, and indirectly through the synthesis and export of organic substances like phytohormones that enhance root growth (10). These two plant growth-promoting effects must be considered separately. The free-living and plant-associated diazotrophic bacteria are ubiquitous in soil, but there is little understanding of

\footnotetext{
* Corresponding author. E-mail: shinano@affrc.go.jp; Tel: +81-11857-9243; Fax: +81-11-857-9243.
}

their diversity and contribution to $\mathrm{N}$ input. This led to our interest in whether any diazotrophic bacterial distribution associated with the rhizosphere of M. malabathricum is unique. We hypothesize that M. malabathricum growing in different soils forms an environment-dependent plant-microorganism relationship and develop different diazotrophic bacterial communities. Comparing the diazotrophic bacterial populations of three soil types may help elucidate their role in the acquisition of $\mathrm{N}$ through the rhizosphere of $M$. malabathricum grown in nutrient-poor soils, such as acid sulfate soil.

Nitrogenase catalyzes BNF and all known nitrogen-fixing organisms are prokaryotes belonging to the bacterial and archaeal domains (25). However, details on the functional diversity of microorganisms in natural environments are still unclear, because more than $99 \%$ of microbial species are refractory to cultivation in the laboratory (3). Recently, several molecular biological methods have been used to describe the structure of diazotrophic bacteria in natural environments (28); such methods that do not use cultivation techniques avoid misinterpretations of the composition of diazotrophic populations. The nifH gene encodes the iron-protein component of nitrogenase, the enzyme necessary for BNF. Since most diazotrophic organisms have nifH, the gene is a useful molecular marker for nitrogen-fixing organisms. Several degenerate primers were designed for PCR-amplification of nifH, based on highly conserved regions of a nifH amino acid sequence $(24,39)$.

Studies have revealed the diversity of the nifH gene in various environments using molecular ecological tools such as clone libraries $(6,12,27,33)$, denaturing gradient gel electrophoresis (DGGE) $(8,19)$, (terminal)-restriction fragment 
length polymorphism (RFLP) $(9,31)$; and a nifH gene-specific macroarray (30). Some studies have focused on the nifH gene pool in the rhizosphere $(6,9,12,19,27,31,33)$. These studies have demonstrated that molecular ecological techniques are useful for describing nifH diversity in the rhizosphere of plants. However, there is limited understanding of the diazotrophic population associated with the rhizosphere of pioneer plants like M. malabathricum. The aim of the present study is to describe the diversity of diazotrophic bacteria in the rhizosphere of $M$. malabathricum grown in three soil types (acid sulfate, peat and sandy clay soils) in south Kalimantan, Indonesia by using molecular ecological techniques as a basis for future microbial applications to agriculture in nutrient-poor soils.

\section{Materials and Methods}

\section{Sampling site}

Rhizosphere soil was collected from M. malabathricum growing naturally in three soil types in the suburbs of Banjarbaru, in south Kalimantan, Indonesia. The three types were classified as acid sulfate, peat and sandy clay soils, respectively, and three plots were examined for each type. All specimens of M. malabathricum sampled were less than $1 \mathrm{~m}$ in height. M. malabathricum was the dominant plant at all sampling sites, and there were few other plant species especially in the acid sulfate soil. However, M. malabathricum grew well at all three sites. Material was collected from one plant per plot for each soil type.

\section{Preparation of the rhizosphere soil}

The root system of M. malabathricum plants was dug up and cut into pieces (10 cm long) to obtain $c a .0 .5 \mathrm{~g}$ of rhizosphere soil. To prevent endophytic contamination of the soil sample, root crosssections were covered with sterilized paraffin. The roots collected from the same plot were mixed and then immersed in a $50-\mathrm{mL}$ conical polyethylene tube containing $40 \mathrm{~mL}$ of sterile phosphate-buffered saline (PBS) for 20 min to remove loosely attached soil; this detached soil fraction was termed "bulk soil". After $20 \mathrm{~min}$, roots were transferred to a new $50-\mathrm{mL}$ conical polyethylene tube containing $40 \mathrm{~mL}$ of sterile PBS. The bulk soil was recovered by centrifugation for $30 \mathrm{~min}\left(6,000 \times \mathrm{g}\right.$, at $\left.4^{\circ} \mathrm{C}\right)$. The tube containing roots with closely adhering soil was shaken for $15 \mathrm{~min}(180 \mathrm{rpm})$ to remove soil. After the roots were removed from the tube, the soil fraction was recovered by centrifugation for $30 \mathrm{~min}(6,000 \times \mathrm{g}$, at $4^{\circ} \mathrm{C}$ ) and termed "rhizosphere soil". Each soil sample was stored at $-20^{\circ} \mathrm{C}$ until DNA extraction.

\section{DNA extraction from soil}

DNA was extracted from the rhizosphere soil of $M$. malabathricum and the bulk soil ( $0.5 \mathrm{~g}$ of each sample) from each plot using ISOIL for Bead Beating (Nippon Gene, Tokyo, Japan) according to the protocol provided by the manufacturer. DNA concentrations were measured with a NanoDrop ND-1000 (NanoDrop Technologies, Rockland, DE, USA).

\section{PCR amplification and clone library-based analysis of nifH genes}

The nifH sequences were amplified using nested PCR to increase sensitivity. The primers used were originally developed by Poly et al. (24). The first PCR was performed with the forward primer FGPH19 (5'-TACGGCAARGGTGGNATHG-3') and reverse primer PolR (5'-ATSGCCATCATYNTCRCCGGA-3'). The second PCR was performed with PolF (5'-TGCGAYCCSAARGCBGACTC-3') and AQER (5'-GACGATGTAGATYTCCTG-3'). The final PCR cocktails contained $2 \mu \mathrm{L}$ of $10 \times$ PCR buffer $\left(\mathrm{Mg}^{2+}\right.$-free $)$, $1.5 \mathrm{mM}$ of $\mathrm{MgCl}_{2}, 0.5 \mu \mathrm{M}$ of each degenerate oligonucleotide primer, $200 \mu \mathrm{M}$ of each deoxynucleoside triphosphate, $8 \mathrm{ng}$ of bovine serum albumin and $1 \mathrm{U}$ of $E x T^{T a}{ }^{\mathrm{TM}}$ (Takara, Otsu, Japan)
DNA polymerase. For the first PCR, $10 \mathrm{ng}$ of the extracted DNA was amplified in Takara Thermal Cycler Dice (Takara). For the second PCR, $1 \mu \mathrm{L}$ of the first PCR product was used as a template. Each mixture was adjusted to a final volume of $20 \mu \mathrm{L}$ with sterile MilliQ water. The reaction profile comprised 30 cycles of denaturation at $94^{\circ} \mathrm{C}$ for $1 \mathrm{~min}$, annealing for $1 \mathrm{~min}$ at $55^{\circ} \mathrm{C}$ for the first PCR and at $48^{\circ} \mathrm{C}$ for the second PCR, and primer extension at $72^{\circ} \mathrm{C}$ for $2 \mathrm{~min}$, with a final extension at $72^{\circ} \mathrm{C}$ for $5 \mathrm{~min}$. The presence of PCR products was determined by analyzing $5 \mu \mathrm{L}$ of product on $2 \%$ agarose gels, and staining with SYBR Green I (Cambrex, East Rutherford, NJ, USA). PCR products ( $c a .340 \mathrm{bp}$ ) were purified with a MinElute PCR Purification Kit (Qiagen, Tokyo, Japan) and cloned into the pGEM-T easy cloning vector (Promega, Madison, WI, USA), according to the manufacturer's instructions. Each clone library was constituted of three replications constructed from PCR products amplified from individually extracted DNAs. Six libraries were constructed for rhizosphere and bulk soils of the three soil types, and $>50$ clones per library were randomly selected to determine the nifH gene sequence.

\section{Sequencing and phylogenetic analysis}

Plasmids were prepared with the QIAprep Miniprep Kit (Qiagen) using the manufacturer's protocol. The cloned fragment was sequenced with a CEQ DTCS-quick start Kit (Beckman Coulter, Fullerton, CA, USA) and a CEQ 8000 sequencing system (Beckman Coulter) using the T7 forward primer.

Phylogenetically unusual nifH sequences were checked for chimeric characteristics by comparing with the GenBank database (DNA Databank of Japan, Shizuoka, Japan) using the blastn program from BLAST search (2) with full-length and partial sequences, and chimeric nifH sequences were omitted from later analysis.

\section{Analyzing the diversity of the nifH gene in rhizospheres of}

M. malabathricum in three soil types

A nifH database based on all the sequences from each nifH clone library was made. Each read was regarded as a query sequence, and sequence identity was computed by a reciprocal blast search of our nifH database using the blastn program 2.2.18 (2). A reciprocal pairwise comparison of two reads yields two sequence identity values. If both values exceeded a certain criterion, the two reads were considered homologous and assembled into one cluster. Any cluster that included $>2$ reads was defined as an operational taxonomic unit (OTU). The criterion for this definition was $85-100 \%$ of the sequence identity value. The number of reads grouped into all OTUs and the number of OTUs at different sequence identity levels are shown in Fig. 1. The criterion for defining an OTU was $94 \%$ of the sequence identity value and only matches as defined above were considered for further analysis. The validity of and grounds for this criterion are mentioned in "Results and Discussion". Reads composing one OTU had the characteristics of nifH libraries, from which these reads were derived (e.g., bulk and rhizosphere soils of

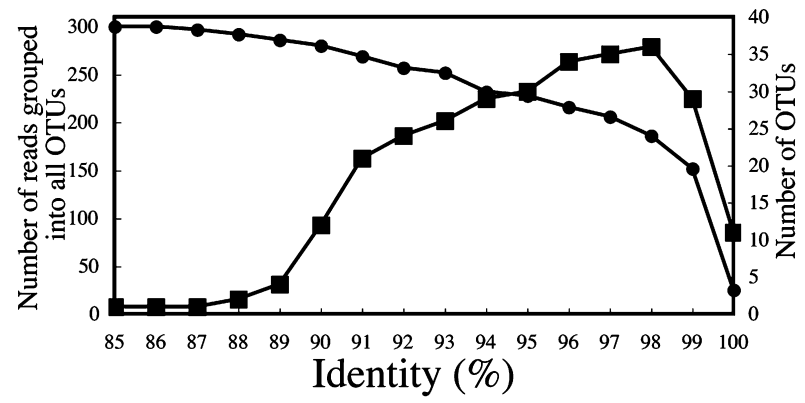

Fig. 1. The number of reads grouped into all operational taxonomic units (OTUs) (O) and the number of OTUs ( $\boldsymbol{\square})$ at different percent identity levels. The number of reads grouped into all OTUs was represented by the summation of reads assembled into all OTUs. 
Table 1. Data matrix of the information on the derivation and number of reads in each soil type

\begin{tabular}{cccccrccccccccccccccccccccccccc}
\hline $\begin{array}{c}\text { Soil } \\
\text { types }^{\mathrm{a}}\end{array}$ & S1 & S2 & S3 & S4 & S5 & S6 & S7 & P1 & P2 & P3 & P4 & P5 & P6 & P7 & P8 & A1 & A2 & A3 & A4 & A5 & A6 & A7 & A8 & A9 & A10 A11 A12 A13 A14 \\
\hline AR & 0 & 0 & 0 & 0 & 0 & 0 & 0 & 0 & 0 & 0 & 0 & 0 & 0 & 0 & 0 & 1 & 0 & 0 & 0 & 0 & 0 & 0 & 1 & 1 & 3 & 22 & 2 & 12 & 4 \\
AB & 0 & 0 & 0 & 0 & 0 & 0 & 0 & 0 & 0 & 0 & 0 & 0 & 0 & 0 & 0 & 9 & 3 & 3 & 3 & 2 & 4 & 6 & 3 & 2 & 2 & 1 & 0 & 0 & 0 \\
PR & 0 & 0 & 0 & 0 & 10 & 0 & 0 & 0 & 0 & 14 & 1 & 2 & 5 & 2 & 2 & 0 & 0 & 0 & 0 & 0 & 0 & 0 & 0 & 0 & 0 & 0 & 0 & 0 & 0 \\
PB & 0 & 0 & 0 & 0 & 7 & 0 & 0 & 2 & 2 & 22 & 2 & 0 & 4 & 1 & 1 & 0 & 0 & 0 & 0 & 0 & 0 & 0 & 0 & 0 & 0 & 0 & 0 & 0 & 0 \\
SR & 2 & 0 & 2 & 2 & 28 & 2 & 3 & 0 & 0 & 0 & 0 & 0 & 0 & 0 & 0 & 0 & 0 & 0 & 0 & 0 & 0 & 0 & 0 & 0 & 0 & 0 & 0 & 0 & 0 \\
SB & 8 & 2 & 0 & 0 & 29 & 1 & 2 & 0 & 0 & 0 & 0 & 0 & 0 & 0 & 0 & 0 & 0 & 0 & 0 & 0 & 0 & 0 & 0 & 0 & 0 & 0 & 0 & 0 & 0 \\
\hline
\end{tabular}

${ }^{a}$ AR, rhizosphere soil from acid sulfate soil; AB, bulk soil from acid sulfate soil; PR, rhizosphere soil from peat soil; PB, bulk soil from peat soil; SR, rhizosphere soil from sandy clay soil; SB, bulk soil from sandy clay soil.
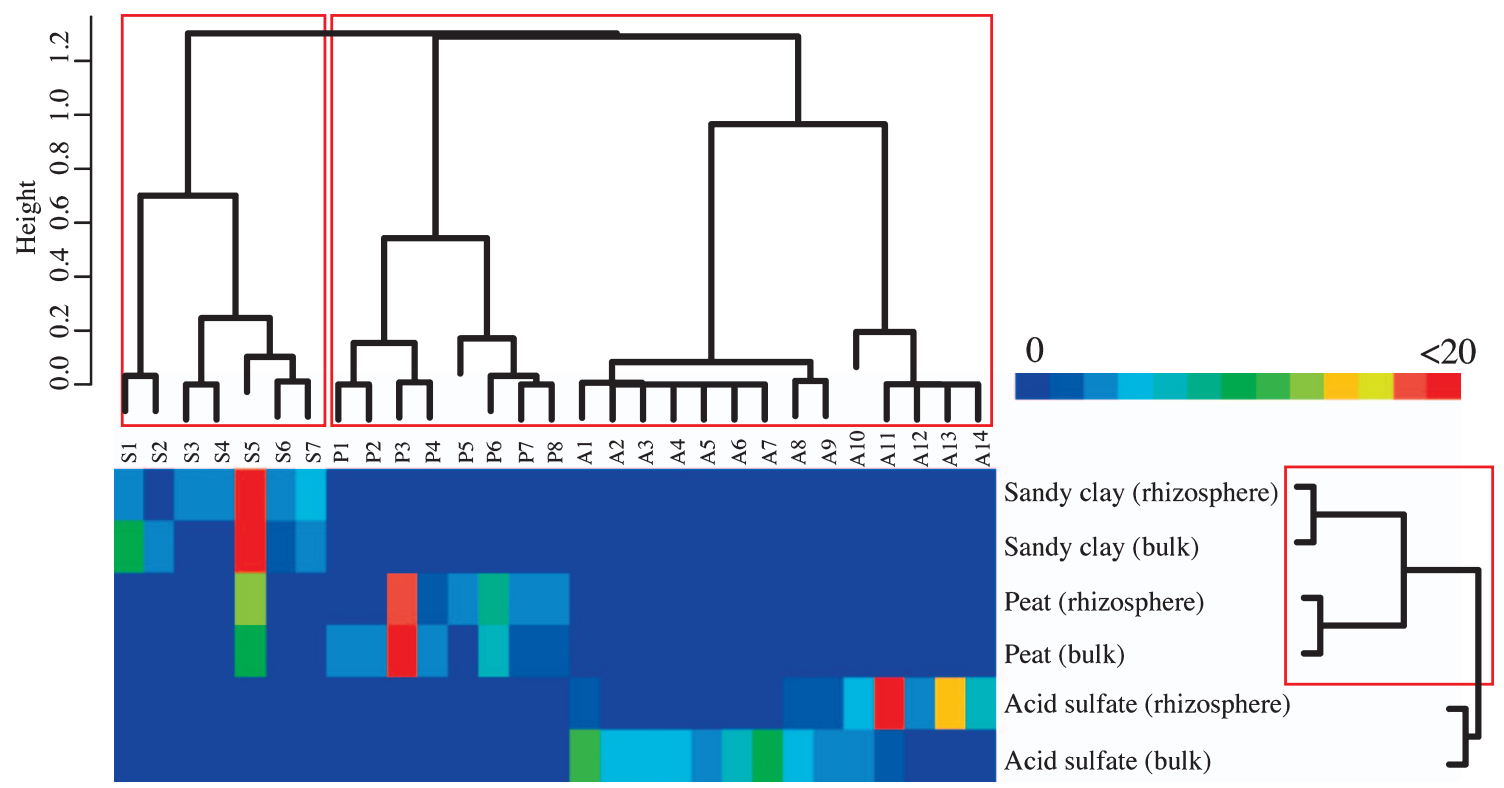

$\begin{array}{llllllllllll}0.0 & 0.2 & 0.4 & 0.6 & 0.8 & 1.0 & 1.2\end{array}$

Height

Fig. 2. Heatmap and dendrograms showing the similarity of nifH clusters (shown on $x$-axis) and those of six different soil types (bulk and rhizosphere soil samples of M. malabathricum in acid sulfate, peat and sandy clay soils, respectively) (on $y$-axis). Each column shows the number of OTUs according to a color scale (shown at the upper right). The dendrogram was constructed using the package pvclust (http://www.is.titech. ac.jp/ shimo/prog/pvclust/), available from The R 2.7.1 program (method.dist=correlation; method.hclust=average; 10,000 bootstrap replications). Clusters with $P<0.05$ are highlighted by rectangles, and are strongly supported by the data.

M. malabathricum in acid sulfate, peat and sandy clay soils, respectively). Each OTU was characterized using information on derivation and the number of reads, and a data matrix for all OTUs was constructed from these two parameters (Table 1). The similarities between both OTUs and soil samples were shown by dendrograms using The R (http://www.R-project.org) based on this data matrix (Fig. 2).

\section{Statistical analysis of nifH gene clone library}

Coverage $(C)$ was calculated to verify whether the nifH gene clone library was large enough to reflect the actual nifH gene pool: $C=1-(n 1 / N)$ where $n 1$ is the number of clones that occurred once and $N$ is the total number of clones (5). The Shannon diversity index (H) (14) was calculated using the software EstimateS 8.0.0 (http:// viceroy.eeb.uconn.edu/estimates).

\section{Nucleotide sequence accession numbers}

All sequences were deposited in DDBJ under accession numbers AB471014 to AB 471313.

\section{Results and Discussion}

\section{Soil properties}

The aim of this study was to describe the diversity of diazotrophic bacteria in the rhizosphere of M. malabathricum. To reduce the effect of differences in climate among sampling sites, the three soil types (acid sulfate, peat and sandy clay soils) were located very close together, thus they can be categorized within the same type of climate and geographic location (Table 2). We checked the properties of the three soils (Table 2). The soils were characterized by soil $\mathrm{pH}\left(\mathrm{H}_{2} \mathrm{O}\right)$, available $\mathrm{P}$ and inorganic $\mathrm{N}$. The acid sulfate soil had a relatively low $\mathrm{pH}\left(\mathrm{H}_{2} \mathrm{O}\right)$, as well as low levels of $\mathrm{P}$ and inorganic $\mathrm{N}$. The peat had a relatively low $\mathrm{pH}\left(\mathrm{H}_{2} \mathrm{O}\right)$, and high levels of available $\mathrm{P}$ and inorganic $\mathrm{N}$. The sandy clay had a relatively high $\mathrm{pH}\left(\mathrm{H}_{2} \mathrm{O}\right)$, low available $\mathrm{P}$ content and small amount of inorganic N. Thus, among the three types, the acid sulfate soil was considered a low-pH and nutrient-poor soil. Nutrient poor soils may have more developed plant-microorganism 
Table 2. Chemical properties of acid sulfate, peat and sandy clay soils

\begin{tabular}{|c|c|c|c|c|c|c|}
\hline Soil type & Samp & ing site & $\mathrm{pH}\left(\mathrm{H}_{2} \mathrm{O}\right)$ & P Bray I (mg kg $\left.{ }^{-1}\right)$ & $\mathrm{NH}_{4}\left(\mathrm{mg} \mathrm{kg}^{-1}\right)$ & $\mathrm{NO}_{3}\left(\mathrm{mg} \mathrm{kg}^{-1}\right)$ \\
\hline Acid sulfate & $03^{\circ} 26^{\prime} 24^{\prime \prime} \mathrm{S}$ & $114^{\circ} 50^{\prime} 50.7^{\prime \prime} \mathrm{E}$ & $3.00-3.22$ & $0.83 \pm 0.00$ & $144 \pm 66$ & $2.2 \pm 3.1$ \\
\hline Peat & $03^{\circ} 26^{\prime} 42.6^{\prime \prime} \mathrm{S}$ & $114^{\circ} 39^{\prime} 57.4^{\prime \prime} \mathrm{E}$ & $3.10-3.75$ & $32.22 \pm 7.06$ & $271 \pm 261$ & $2.0 \pm 2.2$ \\
\hline Sandy clay & $03^{\circ} 26^{\prime} 22.2^{\prime \prime} \mathrm{S}$ & $114^{\circ} 50^{\prime} 57.4^{\prime \prime} \mathrm{E}$ & $4.43-4.75$ & $0.87 \pm 0.48$ & $111 \pm 24$ & $5.7 \pm 6.0$ \\
\hline
\end{tabular}

* The value of $\mathrm{P}$ Bray I, $\mathrm{NH}_{4}$ and $\mathrm{NO}_{3}$ are means \pm SDs ( $=3$ ).

relationships than other soils. Therefore, these three types of soil were considered suitable for investigating whether the diversity of diazotrophic bacteria associated with the rhizosphere of $M$. malabathricum was affected by the properties of soil.

\section{Soil sampling}

There is extensive heterogeneity of microorganisms in natural environments; especially in soil (1). To obtain accurate information on the diversity of diazotrophic bacteria, the method of soil sampling used is vital. Several recent reports have insisted that at least 4-6 plant samples are required to retrieve diazotroph-related genes from rhizosphere soils $(6$, $9,19)$. We sampled the root systems of M. malabathricum from three individual plants in each soil type. We also sampled a large number $(>10)$ of root pieces $(c a .10 \mathrm{~cm})$ from the entire root system of a plant, and then mixed them. Thus, although the number of plants sampled was less than in other reports, the rhizosphere soil was sampled not from one root but from the root system, and then pooled. Thus we consider that DNA extracted from this pool represents DNA of the rhizosphere of the entire root system of M. malabathricum.

\section{PCR amplification targeting the nifH gene}

Kuske et al. (17) demonstrated that the amount of soil template DNA used to initiate PCRs was critical to the detection of target microorganisms. Therefore, the amounts of template DNA for PCR amplification were unified among samples from each soil type.

For PCR, two major nifH-specific primer sets have been used in recent studies. One is the "P-primer" designed by Poly et al. (24), and the other, the "Z-primer" designed by Zehr et al. (39). In this study, we used P-primer for amplification of the nifH gene. When the diversity of the nifH pool in a complex environmental sample was assessed by RTPCR-DGGE, a more detailed fingerprint was detected with Z-primer than with P-primer, due to the presence of mismatches at nondegenerate positions (8). PCR even with Pprimer detected a sufficient fraction of the diversity of the nifH gene pool among each soil type tested (Fig. 2). Thus our result was meaningful enough to describe the diazotrophic diversity in the rhizosphere of $M$. malabathricum, despite the limitations of P-primer.

Nested PCR is useful for detecting low copy-number genes in environmental samples. First, we tried to retrieve the nifH gene fragments from soil samples by PCR only with primers PolF and AQER, but could not (data not shown). As direct amplification failed, to increase sensitivity, the nifH gene fragments were retrieved by nested PCR. Demba Diallo et al. (7) explained that direct amplification failed using PolF and AQER in the first PCR due to quite a low nifH copy number compared with the other nifH gene pools in the sample. Another possible explanation is contamination, by inhibiting substances (e.g., humic acids), of the DNA extracted from soil samples (38). However, in the present study, the purity of extracted DNA was checked photometrically (based on spectra and the A260/230 ratio) and the level of contamination seemed low (data not shown).

\section{Diversity of the nifH gene in the rhizosphere of M. malabathricum in three soil types}

Although there have been many attempts to describe the diversity of nifH gene pools in environmental samples $(6,7$, $9,12,19,30,31,33)$, few studies have simultaneously displayed both qualitative and quantitative differences in nifH gene composition $(18,26,27,32)$. Phylogenetic trees have been frequently used to describe visually the microbial diversity in diverse environments. However, in this study, we tried to illustrate visually the difference in diversity of the nifH gene among soil types. Therefore, we assembled nifH reads into OTUs based on homology, characterized each OTU from the composition of reads, and analyzed the diversity of nifH in samples using a data matrix (Table 1).

The criterion for distinguishing OTUs must be determined prior to analysis. In the case of the $16 \mathrm{~S}$ rRNA gene, sequences with $>97 \%$ identity are typically assigned to the same species, though this criterion is controversial. On the other hand, the cut-off value, adjusted for some ubiquitous single copy protein-coding marker genes (such as AtpD, CyrB, Hsp70, RecA, RpoB and TufA), was defined as $94 \%$ identical at the nucleotide level, and was roughly comparable to the $97 \%$ cut-off commonly used for rRNA (34). Furthermore, Lovell et al. (19) adopted 94\% identity in nucleotide sequence to distinguish OTUs based on nifH gene sequences, and distinguished 29 OTUs (disregarding OTUs with only one read) from 256 nifH reads. The validity of this cut-off value for nifH sequences from the M. malabathricum root system in the present study was verified by comparing the number of reads and the number of OTUs from 85 to $100 \%$ of the cut-off value (Fig. 1). For analyzing diversity, 300 reads were sequenced and assembled into only one OTU at a cut-off value of up to $86 \%$, and 232 reads were assembled into 29 OTUs at a cut-off value of $94 \%$. When the cut-off value was increased further (up to $98 \%$ ), the number of reads decreased and the number of assembled OTUs increased. We defined an OTU as including $>2$ reads, therefore the 68 reads that were not clustered with other reads at the $94 \%$ cut-off value were excluded from the construction of the data matrix, and not used in the subsequent analysis of diversity.

The similarity of OTUs and soil type, according to the composition of nifH reads, were demonstrated through heatmaping by combining two dendrograms (Fig. 2). At $P<0.05$, 
the 29 OTUs were divided into two clusters. The pattern of distribution of OTUs differed between the three soil types, with fourteen nifH clusters (A1-A14) in the acid sulfate soil, eight clusters (P1-P8) in the peat soil, and seven clusters (S1-S7) in the sandy clay soil. The most dominant cluster was A11 in acid sulfate soil, P3 in peat and S5 in sandy clay, respectively. Furthermore, the most closely related organism found in the blastn search was Bradyrhizobium sp. IRBG228 (ca. 90\% identity) for A11, Beijerinckia indica (ca. 85\% identity) for P3 and Mesorhizobium loti (ca. 93\% identity) for S5. Though lateral gene transfer has been speculated for the nitrogenase gene, nifH is considered a useful molecular marker for detecting and identifying diazotrophic organisms, because the phylogeny of the nifH gene generally corresponds to that of the $16 \mathrm{~S}$ rRNA gene (40). Therefore, phylogenetic information on the dominant OTU within each soil type may be useful for inference of function in each soil type. S5 was the only common OTU not found in acid sulfate soil but present in both sandy clay and peat. The pattern of distribution of OTUs differed with soil type. However, a difference between rhizosphere and bulk soils was only found in the acid sulfate soil sample, while the pattern of distribution of OTUs did not differ in the peat and sandy clay soil. There was no OTU existing in all soil samples (i.e. "generalists"). In contrast, there were some OTUs that existed in only one soil sample (i.e. "specialists"). Considering the ubiquitous distribution of free-living diazotrophic bacteria, the lack of generalists among the three soil samples is not compelling. However, in low-nutrient and acid soils, the diversity of the nifH gene might be strongly dependent on soil properties.

\section{Scale of the nifH clone library}

In this study, the clone libraries were constructed from the nifH gene fragments retrieved from rhizosphere and bulk soils of M. malabathricum. Although the accuracy of nifH diversity from the clone library is dependent on the number of nifH reads (i.e. the scale of the nifH clone library), obtaining a large number of nifH reads is a time-consuming and expensive process. Therefore, we checked whether the scale of the nifH clone libraries reflected the number of reads sufficiently to assess the diversity of the nifH gene in natural environments by using $C$ of the libraries (5). At a $94 \%$ cutoff value, the range of $C$ was $78-92 \%$ (Table 3 ). Coelho et al. (6) compared the diversity of nifH gene pools in the rhizosphere of two cultivars of sorghum (Sorghum bicolor) treated with contrasting N levels. Coelho et al. (6) obtained 56-69 reads from each library, and the $C$ of each nifH clone library had a range of $91.8-98.3 \%$. Though the scale of nifH clones in our libraries was similar to their report (we obtained 50 reads from each nifH clone library), our $C$ was relatively low. The reason for this difference is the criterion used for distinguishing OTUs. The criterion for the same clone at the genus level, was determined by the blastn top hit identification (including $<94 \%$ identity) (6). On the other hand, in the present study, only clones with $>94 \%$ identity were regarded as the same clone, even if the blastn top hit indicated the same genus. Therefore, our criterion for distinguishing a clone that appeared only once was stricter than that of Coelho et al. (6). According to the criterion defined by Coelho et al. (6), our $C$ was in the range of $88-98 \%$, in good
Table 3. Shannon diversity index and Coverage index $(C)$ of each nifH clone library

\begin{tabular}{llcc}
\hline Soil types & Fraction & $\begin{array}{c}\text { Shannon diversity } \\
\text { index }\end{array}$ & $\begin{array}{c}\text { Coverage } \\
(\%)\end{array}$ \\
\hline Acid sulfate & Rhizosphere & 1.81 & 92 \\
& Bulk & 2.84 & 76 \\
Peat & Rhizosphere & 2.78 & 72 \\
\multirow{5}{*}{ Sandy clay } & Bulk & 2.33 & 82 \\
& Rhizosphere & 2.82 & 78 \\
& Bulk & 2.05 & 84
\end{tabular}

The Shannon diversity index $(H)$ and $C$ were calculated from 50 reads from each nifH library based on $94 \%$ identity as the criterion for regarding an OTU as the same.

agreement with their results. We concluded that the nifH libraries were sufficiently large to describe the diversity of nifH gene pools in the overall root system of $M$. malabathricum.

\section{The effects of the M. malabathricum rhizosphere}

In this study, we investigated the diversity of diazotrophic bacteria in the habitat around the root of M. malabathricum in three soil types. Several plant species are known to release mucilage composed of detached cells and root exudates, and containing carbohydrates, organic acids, amino acids, vitamins and other compounds, into rhizosphere soil. Up to $20 \%$ of photosynthetically fixed carbon was released into the soil during the vegetative period of spring wheat (15). The amount and/or composition of root exudates released into the rhizosphere varies with plant species, growth stage and other environmental factors $(15,16)$. In hydroponic culture, $M$. malabathricum is one plant species that can exude large amounts of mucilage from its roots (37). It is also known that the activity and biomass of microorganisms are greater in rhizosphere soil than in bulk soil. Bacterial densities, metabolic signatures and genetic structures are also modified by the addition of artificial root exudates to bulk soil (4). Diazotrophic bacteria, which utilize root exudates for their growth, might accumulate in the rhizosphere of plants grown in low-nutrient conditions (11). However, in this study, the pattern of distribution of the nifH gene did not differ significantly between the rhizosphere and bulk soils in peat and sandy clay. There was a large difference in diazotrophic bacterial diversity with soil type. In peat and sandy clay soils, $H$ indicated that the diversity of nifH was higher in rhizosphere than in bulk soil (Table 3). It seems that root exudates did not affect the accumulation of nifH diversity in the rhizosphere. In contrast, in acid sulfate soil, $H$ was lower in the rhizosphere than bulk soil (Table 3). These results indicated that particular bacterial species might accumulate in the rhizosphere of M. malabathricum in acid sulfate soil.

\section{Usefulness of clone libraries and further study}

Molecular biological techniques such as PCR-DGGE and RFLP have been used to compare differences in diazotrophic diversity, based on fingerprint patterns $(7,8,19,31)$. These techniques are suitable for distinguishing existing microbial community structures and provide the advantage of high sample throughput. However, they are unsuited to determining the relative abundance of nifH gene phylotypes and to 
sequencing individual nifH genes constituting a community. On the other hand, by using clone libraries, nifH gene sequences can be determined, revealing the composition of nifH gene pools. Real-time quantitative PCR (qPCR) has been used to determine the abundance of the nifH gene in the oceanic environment and soil $(18,35)$. The information obtained from analyzing clone libraries in this study will be utilized to design specific primer(s) for each respective nifH phylotype with qPCR.

\section{Conclusion}

This study revealed the diversity of the nifH gene associated with $M$. malabathricum roots in three soil types. Our results suggested that the diversity and phylogenetic composition of nifH were dependent on soil properties, and not remarkably different between rhizosphere and bulk soils in peat and sandy clay. However, in acid sulfate soil the diversity of the nifH gene shifted between rhizosphere and bulk soils. The nifH gene sequences were amplified not from RNA but from DNA extracted directly from soil, so the functions and expression of nifH in soil could not be determined. Furthermore, this information does not clarify the role of these diazotrophic bacteria in the supply of $\mathrm{N}$ to $M$. malabathricum. Diazotrophic bacteria may accumulate, depending on their environment, and their role in the acquisition of $\mathrm{N}$ for M. malabathricum may also differ among soil types. Furthermore, the co-culture of diazotrophic bacteria and non-diazotrophic bacteria was reported to enhance or induce nitrogen-fixing activity $(21,29)$. So we need to pay attention to microbial interactions between diazotrophic bacteria and other indigenous bacteria in the rhizosphere of $M$. malabathricum. Further study of the role of diazotrophic bacteria in the rhizosphere of M. malabathricum is progressing. It is also necessary to clarify the relationship between nifH gene expression and root exudates, and to compare the diversity of the nifH gene in the rhizosphere of different plant species.

\section{Acknowledgements}

This project was partly supported by eDNA project, Ministry of Agriculture, Forestry and Fisheries, Japan.

\section{References}

1. Alexander, M. 1961. Introduction to Soil Microbiology. John Wiley \& Sons, Inc., New York, USA.

2. Altschul, S.F., T.L. Madden, A.A. Schäffer, J. Zhang, Z. Zhang, W. Miller, and D.J. Lipman. 1997. Gapped BLAST and PSI-BLAST: A new generation of protein database search programs. Nucleic Acids Res. 25:3389-3402.

3. Amman, R.I., W. Ludwig, and K.H. Schleifer. 1995. Phylogenetic identification and in situ detection of individual microbial cells without cultivation. Microbiol. Rev. 59:143-169.

4. Baudoin, E., E. Benizri, and A. Guckert. 2003. Impact of artificial root exudates on the bacterial community structure in bulk soil and maize rhizosphere. Soil Biol. Biochem. 35:1183-1192.

5. Chelius, M.K., and E.W. Triplett. 2001. The diversity of archaea and bacteria in association with the roots of Zea mays L. Microb. Ecol. 41:252-263.

6. Coelho, M.R.R., M. de Vos, N.P. Carneiro, I.E. Marriel, E. Paiva, and L. Seldin. 2008. Diversity of nifH gene pools in the rhizosphere of two cultivars of sorghum (Sorghum bicolor) treated with contrasting levels of nitrogen fertilizer. FEMS Microbiol. Lett. 279:15-22.

7. Demba Diallo, M., A. Willems, N. Vloemans, and et al. 2004 Polymerase chain reaction denaturing gradient gel electrophoresis analysis of the $\mathrm{N}_{2}$-fixing bacterial diversity in soil under Acacia tortilis ssp. raddiana and Balanites aegyptiaca in the dryland part of Senegal. Environ. Microbiol. 6:400-415.

8. Demba Diallo, M., B. Reinhold-Hurek, and T. Hurek. 2008. Evaluation of PCR primers for universal nifH gene targeting and for assessment of transcribed nifH pools in roots of Oryza longistaminata with and without low nitrogen input. FEMS Microbiol. Ecol. 65:220-228.

9. Deslippe, J.R., and K.N. Egger. 2006. Molecular diversity of nifH genes from bacteria associated with high arctic dwarf shrubs. Microb. Ecol. 51:516-525.

10. Dobbelaere, S., J. Vanderleyden, and Y. Okon. 2003. Plant growthpromoting effects of diazotrophs in the rhizosphere. Crit. Rev. Plant Sci. 22:107-149.

11. Döbereiner, J., and F.O. Pedrosa. 1987. Nitrogen-Fixing Bacteria in Nonleguminous Crop Plants. Science Tech, Inc., Madison, WI, USA.

12. Hamelin, J., N. Fromin, S. Tarnawski, S. Teyssier-Cuvelle, and M. Aragno. 2002. nifH gene diversity in the bacterial community associated with the rhizosphere of Molinia coerulea, an oligonitrophilic perennial grass. Environ. Microbiol. 4:477-481.

13. Hashidoko, Y., Y. Gotou, M. Osaki, E. Purnomo, L.H. Suwido, and S. Tahara. 2006. Characterization and ecological role of free-living nitrogen-fixing bacteria isolated from the rhizoplane of Melastoma malabathricum inhabiting acidic plain lands in Kalimantan. Tropics 15:365-369.

14. Hayek, L.A.C., and M.A. Buzas. 1997. Surveying Natural Populations. Columbia University Press, New York, USA.

15. Hütsch, B.W., J. Augustin, and W. Merbach. 2002. Plant rhizodeposition - an important source for carbon turnover in soils. J. Plant Nutr. Soil Sci. 165:397-407.

16. Kuiper, I., L.V. Kravchenko, G.V. Bloemberg, and B.J.J. Lugtenberg. 2002. Pseudomonas putida strain PCL1444, selected for efficient root colonization and naphthalene degradation, effectively utilizes root exudate components. Mol. Plant-Microbe Interact. 15:734-741.

17. Kuske, C.R., K.L. Banton, D.L. Adorada, P.C. Stark, K.K. Hill, and P.J. Jackson. 1998. Small-scale DNA sample preparation method for field PCR detection of microbial cells and spores in soil. Appl. Environ. Microbiol. 64:2463-2472.

18. Langlois, R.J., D. Hümmer, and J. LaRoche. 2008. Abundances and distributions of the dominant nifH phylotypes in the Northern Atlantic Ocean. Appl. Environ. Microbiol. 74:1922-1931.

19. Lovell, C.R., P.V. Decker, C.E. Bagwell, S. Thompson, and G.Y. Matsui. 2008. Analysis of a diverse assemblage of diazotrophic bacteria from Spartina alterniflora using DGGE and clone library screening. J. Microbiol. Methods 73:160-171.

20. Marschner, H. 1995. Mineral Nutrition of Higher Plants. Academic Press, London, UK.

21. Minamisawa, M., K. Nishioka, T. Miyaki, and et al. 2004. Anaerobic nitrogen-fixing consortia consisting of clostridia isolated from gramineous plants. Appl. Environ. Microbiol. 70:3096-3102.

22. Osaki, M., M. Matsumoto, T. Watanabe, T. Kawamukai, T. Shinano, T. Nuyim, C. Nilnond, and T. Tadano. 1998. Strategies for adaptation of plants grown in adverse soils, p. 537-546. In N.E. Bassam, R.K. Behl, and B. Prochnow (ed.), Sustainable Agriculture for Food, Energy, and Industry. James \& James Ltd., London, UK.

23. Osaki, M., T. Watanabe, T. Ishizawa, C. Nilnond, T. Nuyim, C. Sittibush, and T. Tadano. 1998. Nutritional characterisitics in leaves of native plants grown in acid sulfate, peat, sandy podzolic, and saline soils distributed in Peninsular Thailand. Plant Soil 201:175182.

24. Poly, F., L.J. Monrozier, and R. Bally. 2001. Improvement in the RFLP procedure for studying the diversity of nif $H$ genes in communities of nitrogen fixers in soil. Res. Microbiol. 152:95-103.

25. Raymond, J., J.L. Siefert, C.R. Staples, and R.E. Blankenship. 2004. The natural history of nitrogen fixation. Mol. Biol. Evol. 21:541-554

26. Reiter, B., H. Bürgmann, K. Burg, and A. Sessitsch. 2003. Endophytic nifH gene diversity in African sweet potato. Can. J. Microbiol. 49:549-555.

27. Roesch, L.F.W., F.A.O. Camargo, F.M. Bento, and E.W. Triplett. 2008. Biodiversity of diazotrophic bacteria within the soil, root and stem of field-grown maize. Plant Soil 302:91-104.

28. Saito, A., S. Ikeda, H. Ezura, and K. Minamisawa. 2007. Microbial 
community analysis of the phytosphere using culture-independent methodologies. Microbes Environ. 22:93-105.

29. Shrestha, A., K. Toyota, M. Okazaki, Y. Suga, M.A. Quevedo, A.B. Loreto, and A.A. Mariscal. 2007. Enhancement of nitrogen-fixing activity of Enterobacteriaceae strains isolated from sago palm (Metroxylon sagu) by microbial interaction with non-nitrogen fixers. Microbes Environ. 22:59-70.

30. Steward, G.F., B.D. Jenkins, B.B. Ward, and J.P. Zehr. 2004. Development and testing of a DNA macroarray to assess nitrogenase (nifH) gene diversity. Appl. Environ. Microbiol. 70:1455-1465.

31. Tan, Z., T. Hurek, and B. Reinhold-Hurek. 2003. Effect of N-fertilization, plant genotype and environmental conditions on nifH gene pools in roots of rice. Environ. Microbiol. 5:1009-1015.

32. Terakado-Tonooka, J., Y. Ohwaki, H. Yamakawa, F. Tanaka, T. Yoneyama, and S. Fujihara. 2008. Expressed nifH genes of endophytic bacteria detected in field-grown sweet potatoes (Ipomoea batatas L.). Microbes Environ. 23:89-93.

33. Ueda, T., Y. Suga, N. Yahiro, and T. Matsuguchi. 1995. Remarkable $\mathrm{N}_{2}$-fixing bacterial diversity detected in rice roots by molecular evolutionary analysis of nifH gene sequences. J. Bacteriol. 177:1414 1417.
34. Venter, J.C., K. Remington, J.F. Heidelberg, and et al. 2004. Environmental genome shotgun sequencing of the Sargasso Sea. Science 304:66-74.

35. Wallenstein, M.D., and R.J. Vilgalys. 2005. Quantitative analyses of nitrogen cycling genes in soils. Pedobiologia 49:665-672.

36. Watanabe, T., M. Osaki, T. Yoshihara, and T. Tadano. 1998. Distribution and chemical speciation of aluminum in the $\mathrm{Al}$ accumulator plant, Melastoma malabathricum L. Plant Soil 201:165-173.

37. Watanabe, T., S. Misawa, S. Hiradate, and M. Osaki. 2008. Characterization of root mucilage from Melastoma malabathricum, with emphasis on its roles in aluminum accumulation. New Phytol. 178:581-589.

38. Wilson, I.G. 1997. Inhibition and facilitation of nucleic acid amplification. Appl. Environ. Microbiol. 63:3741-3751.

39. Zehr, J.P., and L.A. McReynolds. 1989. Use of degenerate oligonucleotides for amplification of the nifH gene from the marine cyanobacterium Trichodesmium thiebautii. Appl. Environ. Microbiol. 55:2522-2526.

40. Zehr, J.P., B.D. Jenkins, S.M. Short, and G.F. Steward. 2003. Nitrogenase gene diversity and microbial community structure: A crosssystem comparison. Environ. Microbiol. 5:539-554. 